\title{
Sporadic Intragenic Inversion of the Mitochondrial DNA MTND1 Gene Causing Fatal Infantile Lactic Acidosis
}

\author{
EMMA L. BLAKELY, KATHERINE J. RENNIE, LINDA JONES, MATTIAS ELSTNER, \\ ZOFIA M. A. CHRZANOWSKA-LIGHTOWLERS, CHRISTOPHER B. WHITE, JULIAN P. H. SHIELD, \\ DANIELA T. PILZ, DOUGLASS M. TURNBULL, JOANNA POULTON, AND ROBERT W. TAYLOR
}

\begin{abstract}
Mitochondrial Research Group [E.L.B., K.J.R., M.E., Z.M.A.C.-L., C.B.W., D.M.T., R.W.T.], School of Neurology, Neurobiology and Psychiatry, The University of Newcastle upon Tyne, Newcastle upon Tyne NE2 4HH, UK; Institute of Medical Genetics [L.J., D.T.P.], University Hospital of Wales, Cardiff CF14 4XW, UK; The Royal Hospital for Children [J.P.H.S.], Bristol BS2 8AE, UK; Department of Obstetrics and Gynaecology [J.P.], John Radcliffe Hospital, Oxford OX3 9DU, UK
\end{abstract}

\begin{abstract}
Mutations of mitochondrial DNA (mtDNA) are an important cause of genetic disease, yet rarely present in the neonatal period. Here we report the clinical, biochemical, and molecular genetic findings of an infant who died at the age of 1 mo with marked biventricular hypertrophy, aortic coarctation, and severe lactic acidosis due to a previously described but unusual mtDNA mutation, a 7-bp intragenic inversion within the mitochondrial gene encoding ND1 protein of complex I (MTND1). In direct contrast to the previous case, an adult with exercise intolerance who only harbored the mutation in muscle, the MTND1 inversion in our patient was present at high levels in several tissues including the heart, muscle, liver, and cultured skin fibroblasts. There was no evidence of the mutation or respiratory complex I defect in a muscle biopsy from the patient's mother. Transmitochondrial cytoplasmic hybrids (cybrids) containing high mutant loads of the inversion expressed the biochemical defect but apparently normal levels of the assembled complex. Our report highlights the enormous phenotypic diversity that exists among pathogenic mtDNA mutations and reemphasizes the need for appropriate genetic counseling for families affected by mtDNA disease. (Pediatr Res 59: 440-444, 2006)
\end{abstract}

$\mathrm{M}^{\mathrm{i}}$ itochondrial genetic disorders due to impairment of oxidative phosphorylation are both fascinating and common. They may be caused by mutations in genes encoded by either the nuclear or mitochondrial genome (mtDNA) and are associated with a diverse and ever-growing spectrum of clinical presentations $(1,2)$.

Isolated complex I deficiency is the most commonly reported enzyme defect in mitochondrial disorders $(3,4)$ and is associated with a wide range of clinical presentations in both children and adults. In most children with complex I deficiency, the family history is consistent with sporadic or autosomal recessive inheritance, and, although nuclear gene mutations have been assumed to account for more than $90 \%$ of cases (5), definitive mutations have been identified in only a

Received July 13, 2005; accepted September 30, 2005.

Correspondence: Robert W. Taylor, Ph.D., Mitochondrial Research Group, School of Neurology, Neurobiology and Psychiatry, University of Newcastle upon Tyne, Newcastle upon Tyne, NE2 4HH, UK; e-mail: r.w.taylor@ncl.ac.uk

This work was supported by grants from the Wellcome Trust, Muscular Dystrophy Campaign and Newcastle upon Tyne Hospitals NHS Trust to D.M.T. and R.W.T. M.E. is supported by the European Neurological Society.

DOI: $10.1203 / 01 . p d r .0000198771 .78290 . c 4$ small number of cases (6). Conversely, mtDNA mutations have been perceived as rare causes of pediatric complex I deficiency. However, extensive sequencing of the mitochondrial genome has now revealed a number of recurrent mutations in mitochondrial complex I (MTND) genes in infantile mitochondrial encephalopathies such as Leigh syndrome and lethal infantile mitochondrial disease and mitochondrial myopathy, encephalopathy, lactic acidosis, and strokelike episodes (MELAS) syndrome (7-15). Although very few of these children have a family history suggestive of an mtDNA mutation, these data suggest that the prevalence of pathogenic mtDNA mutations in pediatric complex I deficiency may be as high as $25 \%$ (16).

We report on an infant who presented in the neonatal period with marked biventricular hypertrophy, aortic coarctation, and a severe lactic acidosis as a consequence of a 7-bp intragenic inversion in the mitochondrial MTND1 gene. Interestingly, this unusual mutation has been described previously in an adult patient with isolated complex I deficiency, ragged-red fibers, and exercise intolerance (17). In contrast to the previous case in which the mutation appeared to be restricted to skeletal muscle, the MTNDI inversion was present at high levels in several tissues including cultured skin fibroblasts, which has allowed us to generate cybrid fusions to further investigate the underlying complex I defect.

\section{CASE REPORT}

The proband, a female, was the first child of healthy, unrelated parents. There was no family history of note. She was a home delivery at term and weighed $2.67 \mathrm{~kg}$ (ninth centile). In view of meconium staining of the liquor, she was admitted to hospital for observation. A heart murmur was noted, and investigations revealed marked biventricular hy-

Abbreviations: BN-PAGE, blue-native polyacrylamide gel electrophoresis; cybrid, transmitochondrial cytoplasmic hybrid; mtDNA, mitochondrial DNA; MTND1, mitochondrial gene encoding ND1 protein of complex I 
pertrophy, coarctation of the aorta, and a perimembranous ventricular septal defect. She had a persisting metabolic acidosis with a base deficit of 15-20 and high plasma lactate levels $(11.28 \mathrm{mmol} / \mathrm{L}$ on day 2 ; normal range, $0.63-2.44$ $\mathrm{mmol} / \mathrm{L}$ ), which persisted despite being stabilized on a prostaglandin infusion. A respiratory chain defect was suspected, supported by her significantly elevated cerebrospinal fluid lactate $(7.14 \mathrm{mmol} / \mathrm{L}$ on $\mathrm{d} 8$ of life), and a high plasma alanine level of $837 \mu \mathrm{mol} / \mathrm{L}$ (normal range, $120-600 \mu \mathrm{mol} / \mathrm{L}$ ) with a plasma lactate-to-pyruvate ratio of 33 (normal range, <15). The lactic acidemia was thought to be out of proportion to the severity of her aortic coarctation and other cardiac anomalies.

At the age 2 weeks, it was decided to correct the cardiac lesion and a skeletal muscle biopsy was taken at the same time for respiratory chain analysis. Although surgery was entirely successful with good circulatory function, the child's condition deteriorated. She had a significant metabolic lactic acidosis associated with a worsening hypertrophic cardiomyopathy and developed frequent apnea and desaturations. Supportive therapy was withdrawn, and the child died at age 4 wk. A full postmortem examination was declined, but some tissues (heart and liver) were available for analysis. Karyotyping and 22q11 deletion analysis were both normal.

The proband's muscle biopsy demonstrated normal staining for succinate dehydrogenase, cytochrome $c$ oxidase, and phosphorylase activities. Staining for reduced nicotinamide adenine dinucleotide (NADH) reductase was normal as were ATPase stains for distribution of type 1 and 2 fibers. No ultrastructural abnormalities were detected on electron microscopy. Analysis of respiratory chain enzyme activities by another diagnostic center revealed complex I activity on the low side of the normal range (patient, 0.104; normal range, 0.104-0.268), but this result was not thought to be conclusive or liable in itself to manifest as such a severe clinical illness. With the clinical course still suggestive of a mitochondrial disorder, mtDNA studies were subsequently pursued, with the proband's mother also consenting to a muscle biopsy. All studies were performed with the approval of the Newcastle and North Tyneside Research Ethics Committee.

\section{METHODS}

Muscle histochemistry and biochemistry. Histologic and histochemical analyses were performed using standard procedures. The activities of the individual respiratory chain complexes were measured in a post- $600 \mathrm{~g}_{\mathrm{av}}$ skeletal muscle supernatant and an enriched mitochondrial fraction isolated from cybrid clones, and expressed relative to the activity of the matrix marker enzyme citrate synthase (18).

mtDNA sequencing. Total DNA was extracted from several tissues by standard procedures, and the entire mitochondrial genome was amplified from patient heart DNA using a series of M13-tailed oligonucleotide primer pairs essentially as described elsewhere (19).

Restriction fragment length polymorphism (RFLP) analysis of the MTND1 intragenic inversion mutation. A 200-bp fragment encompassing the MTND1 inversion was amplified using the mismatched forward primer previously described by Musumeci et al. (17) and a reverse primer with the following sequence: (4075-4054) 5' TTGTGTAGAGTTCAGGGGAGAG 3'. The mismatch in the sense primer creates an additional Fnu4H I restriction site in the mutant polymerase chain reaction (PCR) product (Fig. 1), permitting discrimination between wild-type and mutated mtDNA.

The relative proportion of wild-type and mutated mtDNA genomes was determined by the addition of $5 \mu \mathrm{Ci}\left[\alpha^{-}{ }^{32} \mathrm{P}\right]$ deoxycytidine triphosphate (3000 $\mathrm{Ci} / \mathrm{mmol}$ ) before the last cycle of the PCR. Labeled products were digested
$\boldsymbol{A}$

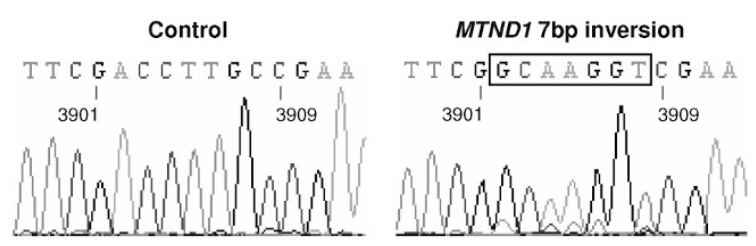

B

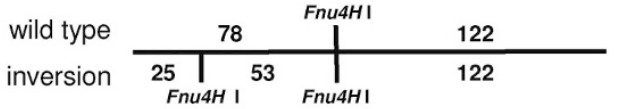

C

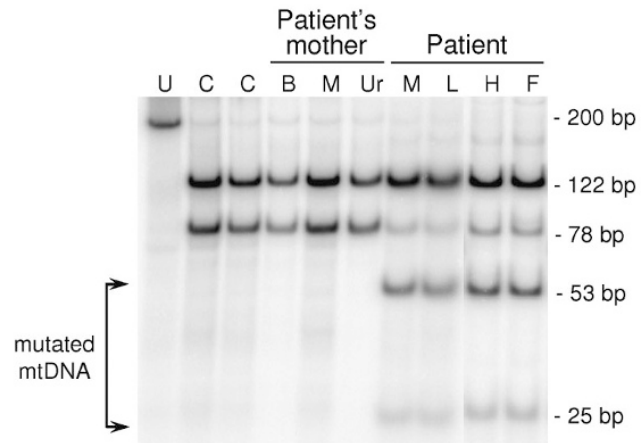

Figure 1. Identification and molecular genetic analysis of the MTND1 inversion. (A) Sequence electropherograms of the MTND1 gene showing the heteroplasmic inversion of seven nucleotides in the patient compared with the control. (B) Schematic of the PCR-RFLP assay to assess mtDNA heteroplasmy at this site, showing the expected restriction products following digestion of radiolabeled products with $F n u 4 H$ I. (C) Quantification of the relative amounts of mutated and wild-type mtDNA in different tissues from the patient and her unaffected mother. A mismatch in the sense primer creates an additional $F n u 4 H$ I restriction site in the mutated PCR product, yielding fragments of 53 and $25 \mathrm{bp}$. U, uncut sample; C, control; B, blood; M, skeletal muscle; Ur, urinary sediment; L, liver; $\mathrm{H}$, heart; F, fibroblasts.

with $10 \mathrm{U}$ of $F n u 4 H$ I (New England Biolabs), separated through a 12\% nondenaturing polyacrylamide gel, and the radioactivity in each fragment quantified using ImageQuant software (Amersham/GE Healthcare).

Generation of cybrids. Cybrids were generated by fusing enucleated patient fibroblasts with the $143 \mathrm{~B} .206 \rho^{0}$ osteosarcoma cell line using polyethylene glycol 1500 as previously described (20). To select against any nonenucleated donor cells, bromodeoxyuridine $\left(100 \mu \mathrm{g} \cdot \mathrm{mL}^{-1}\right)$ was added to the culture medium $24 \mathrm{~h}$ after fusion. Selected cybrids were initially grown as a population before independent clones were isolated and expanded, and the level of mtDNA heteroplasmy determined by PCR-RFLP analysis as described above.

Measurement of respiration in cybrid cells. Polarographic studies were carried out essentially as previously described $(21,22)$. Approximately $2-3 \times$ $10^{6}$ exponentially growing cells were harvested and resuspended in $2 \mathrm{~mL}$ of a Tris-based $\mathrm{Mg}^{2+}-, \mathrm{Ca}^{2+}$-deficient (TD) buffer $(137 \mathrm{mmol} / \mathrm{L} \mathrm{NaCl}, 5$ $\mathrm{mmol} / \mathrm{L} \mathrm{KCl}, 0.7 \mathrm{mmol} / \mathrm{L} \mathrm{Na}_{2} \mathrm{HPO}_{4}, 25 \mathrm{mmol} / \mathrm{L} \mathrm{Tris}-\mathrm{HCl}, \mathrm{pH} 7.4$ at $25^{\circ} \mathrm{C}$ ) or a Tris-based permeabilization $(\mathrm{PB})$ buffer $(75 \mathrm{mmol} / \mathrm{L}$ sucrose, $5 \mathrm{mmol} / \mathrm{L}$ potassium phosphate, $40 \mathrm{mmol} / \mathrm{L} \mathrm{KCl}, 0.5 \mathrm{mmol} / \mathrm{L}$ ethylenediamine tetraacetic acid, $3 \mathrm{mmol} / \mathrm{L} \mathrm{MgCl}_{2}, 0.35 \% \mathrm{BSA}, 30 \mathrm{mmol} / \mathrm{L}$ Tris- $\mathrm{HCl}, \mathrm{pH} 7.4$ at $25^{\circ} \mathrm{C}$ ) and introduced into a high-resolution oxygraph chamber (Oroboros, Innsbruck) at $37^{\circ} \mathrm{C}$. The cells resuspended in TD buffer were read directly or after the addition of 2,4-dinitrophenol (DNP). Cells resuspended in PB buffer were permeabilized by the addition of digitonin $\left(15 \mu \mathrm{g} / 1 \times 10^{6}\right.$ cells $)$, and traces were read after multiple substrate-inhibitor titration as described (21). Individual inhibitor-sensitive oxygen consumption rates were calculated as the time derivative of the oxygen concentration (DATLAB Analysis Software, Oroboros) and analyzed using SPSS software.

Western blotting. Mitochondrial samples $(20 \mu \mathrm{g})$ were separated by $15 \%$ sodium dodecylsulfate (SDS)-PAGE and immobilized by wet transfer (100 V, $1 \mathrm{~h}$ ) onto polyvinylidene fluoride (PVDF) (Immobilon-P, Millipore Corpora- 
tion) membrane in $25 \mathrm{mmol} / \mathrm{L}$ Tris, $192 \mathrm{mmol} / \mathrm{L}$ glycine, $0.02 \%$ (wt:vol) SDS, $15 \%$ (vol:vol) methanol. Proteins of interest were bound by mouse monoclonal antibody to the 39-kD (NDUFA9) and 20-kD (MTND6) subunits of complex I and the 30-kD iron-sulfur protein subunit (SDHB) of complex II, followed by horseradish peroxidase-conjugated secondary (Dako) and visualized with Enhanced Chemiluminescence (ECL) plus reagents (Amersham Biosciences).

Blue-native polyacrylamide gel electrophoresis (BN-PAGE). BN-PAGE of cybrid and 143B parental control mitochondrial fractions and mitochondrial complexes I and IV in-gel activity assays were performed as previously described (23).

\section{RESULTS AND DISCUSSION}

A lack of tissue meant that further biochemical studies were not possible on the proband's postmortem samples. Histochemical and biochemical examination of the mother's muscle biopsy, however, failed to demonstrate any evidence of mitochondrial dysfunction, with completely normal activity of complexes I, II, and IV (data not shown).

mtDNA rearrangements and mtDNA depletion syndrome were excluded by Southern blot analysis, and a screen for common mtDNA mutations including $3243 \mathrm{~A}>\mathrm{G}$ and $8344 \mathrm{~A}>\mathrm{G}$ also proved negative. Direct sequencing of the entire mtDNA genome was undertaken, revealing a previously reported pathogenic mutation, a 7-bp intragenic inversion within the MTND1 gene (Fig. 1A) that alters three very highly conserved amino acids in the MTND1 polypeptide (17). We designed an RFLP assay to investigate the distribution of the MTND1 inversion in several available tissues (Fig. $1 B$ ) and were clearly able to demonstrate high levels of heteroplasmy not only in skeletal muscle (84\%), but also in the liver (87\%), heart (85\%), and cultured skin fibroblasts (70\%) (Fig. 1C). Interestingly, the mutation was clearly absent from all tissues from the patient's mother, including skeletal muscle, suggesting that the pathogenic inversion had arisen sporadically within the oocyte, similar to single, large-scale mtDNA deletions (24).

To further study the MTND1 inversion, cybrids were generated using the patient fibroblasts and several clones isolated (Fig. 2A). For one clone (MTNDlinv-A2) harboring 91\% mutated mtDNA, cells were expanded to measure both respiratory chain enzyme activity in isolated mitochondrial fractions and whole cell respiration. A significant reduction of complex I activity (24\% of control activity) was noted in the patient-derived cybrid clone when compared with the 143B parental cells (Fig. 2B), whereas the activity of complex IV was normal. Furthermore, whole-cell respiration studies showed a clear decrease in complex I-linked substrate oxidation using both glutamate + malate $(41 \%$ of controls) and pyruvate + malate $(36 \%$ of controls) and respiratory reserve capacity in the patient-derived cybrid clone, although the oxidation of succinate + glycerol-3-phosphate (measuring complexes II and III) and $\mathrm{N}, \mathrm{N}, \mathrm{N}^{\prime}, \mathrm{N}^{\prime}$-tetramethyl-pphenylenediamine (TMPD) + ascorbate (measuring complex IV) were unremarkable compared with the 143B parental cells (Fig. 2C).

To study the assembly of complex I, we performed onedimensional (1D) BN-PAGE and Western blotting on mitochondrial proteins extracted from the cybrid clone and the 143B parental cells. In agreement with the spectrophotometric
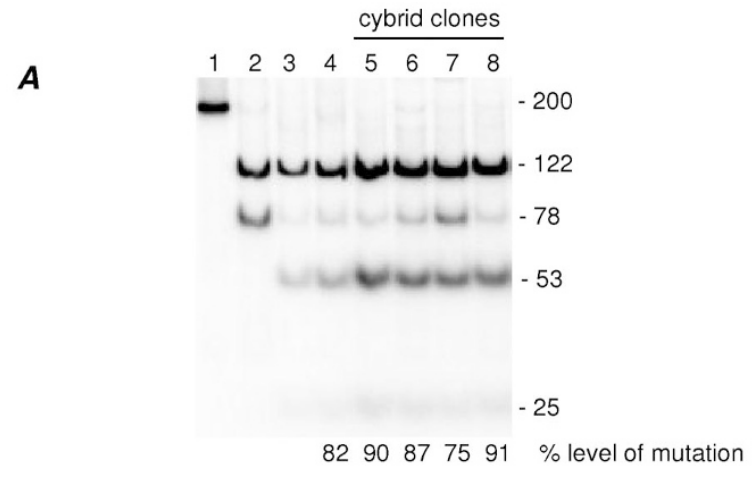

B

COMPLEX

Complex I / Citrate Synthase Complex IV / Citrate Synthase

C

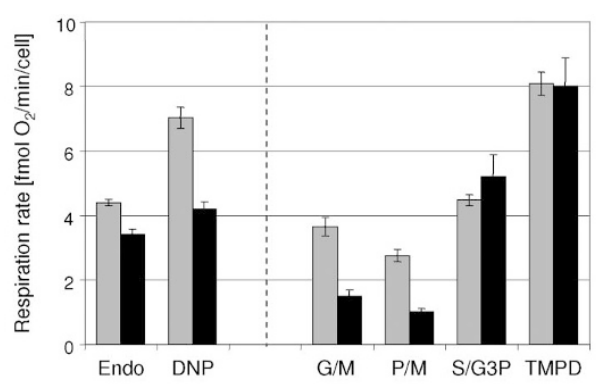

Figure 2. Analysis of MTND1 intragenic inversion in 143B cybrid cells. $(A)$ RFLP analysis of four independent cybrid clones (lanes 5-8) harboring different levels of the heteroplasmic inversion. Clone MTND1inv-A2 (lane 8) was chosen for further analysis. Lane 1, uncut; lane 2, control; lane 3, patient liver sample; lane 4, uncloned cybrid fusions. (B) Respiratory chain enzyme activity in the cybrid clone MTND1inv-A2, highlighting the isolated defect in complex I. Activity is expressed as $\mathrm{nmol} \mathrm{NADH}$ oxidized $\cdot \mathrm{min}^{-1} \cdot$ unit citrate synthase ${ }^{-1}$ for complex $\mathrm{I}$ and the apparent first-order rate constant $\cdot \sec ^{-1} \cdot$ unit citrate synthase ${ }^{-1}$ for complex IV $\left(\times 10^{3}\right)$. (C) Polarographic measurement of endogenous, DNP-uncoupled ( $30 \mu \mathrm{mol} / \mathrm{L})$ and substrate-dependent respiration of 143B parental cells (shaded columns) and the mutant clone MTND1inv-A2 (black columns). Glutamate + malate (G/M, 5 $\mathrm{mmol} / \mathrm{L}$ each) and pyruvate + malate $(\mathrm{P} / \mathrm{M}, 5 \mathrm{mmol} / \mathrm{L}$ each) were inhibited with rotenone (100 nmol/L), succinate + glycerol-3-phosphate (S/G3P, 5 $\mathrm{mmol} / \mathrm{L}$ each) by antimycin $(20 \mathrm{nmol} / \mathrm{L})$ and TMPD + ascorbate (TMPD 0.4 $\mathrm{mmol} / \mathrm{L}$, sodium ascorbate $10 \mathrm{mmol} / \mathrm{L})$ by $\mathrm{KCN}(2 \mathrm{mmol} / \mathrm{L})$. Data shown represent inhibitor-sensitive values as the means \pm standard error of three determinations and are expressed in $\mathrm{fmol} \mathrm{O}_{2} \cdot \min ^{-1} \cdot$ cell $^{-1}$.

measurements, 1D BN-PAGE revealed a decrease in the in-gel activity of complex I in the cybrid clone harboring high levels of the MTND1 inversion compared with the 143B parental cells, although to a lesser degree (approximately $60 \%$ of control) (Fig. 3A). As expected, complex IV activity was normal. Western blotting, however, did not show any obvious decrease in the steady state levels of either mtDNA-encoded or nuclear-encoded complex I subunits (Fig. 3B), implying that the inversion affects catalysis or electron transfer through the complex but does not interfere directly with complex I assembly. As previously highlighted, the 7-bp inversion causes an in-frame substitution of three amino acids (AspLeu-Ala at positions 199-201 to Gly-Lys-Val) in a highly 


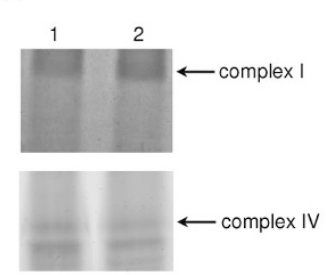

$B$

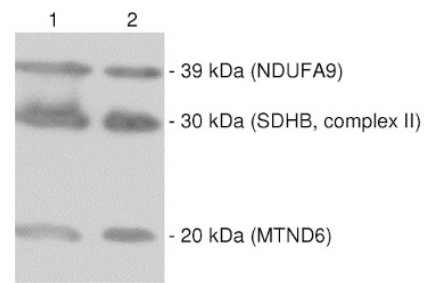

Figure 3. BN-PAGE and Western blotting. (A) BN-PAGE and in-gel activity assays were done exactly as described (21) with $100 \mu \mathrm{g}$ mitochondrial protein loaded onto the gel for both the MTNDlinv-A2 cybrid clone (lane 1) and the 143B parental cell line (lane 2). (B) For immunoblotting experiments, equal amounts $(20 \mu \mathrm{g})$ of protein from the cybrid clone (lane 1) and the 143B parental control (lane 2) were subjected to SDS-PAGE and blotted onto a PVDF membrane before incubation with monoclonal antibody as described in the Methods section.

conserved region of the MTND1 protein that is thought to play a role in ubiquinone binding (25) and as such would have a detrimental effect on enzyme activity. Interestingly, this result is in contrast to three recently reported missense mutations in the MTND1 gene, all of which severely disrupt both complex I activity and assembly (15).

Perhaps the most significant finding is the marked contrast in clinical presentation and course between our patient and the only other case with the identical MTNDl inversion described by DiMauro and coworkers (17). Their patient initially presented in childhood, but was still experiencing exercise intolerance and myalgia in his 40s. His muscle biopsy was markedly abnormal with approximately $40 \%$ of fibers demonstrating mitochondrial accumulation, yet despite this, the respiratory chain defect involving complex I was apparently mild (40\% of controls). The inversion was not present in either his or his mother's blood, with no family history of note, and it was presumed that the mutation arose sporadically and was restricted to muscle, similar to other pathogenic mtDNA mutations associated with this phenotype (26). Our patient presented with early onset of lactic acidosis and severe cardiac abnormalities. Whereas biventricular cardiac hypertrophy is commonly described in patients with mtDNA disease, coarctation of the aorta is unusual, although it is not known whether this was related to the underlying mitochondrial abnormality. Although biochemical analyses were not possible on postmortem tissue, genetic studies clearly demonstrated high levels of the MTND1 inversion in several tissues including the heart, the clinically affected tissue, and even cultured skin fibroblasts. Unlike the previous case, however, there was no evidence of ragged-red fibers.

Our investigation of this family also raised further important questions relating to the ongoing debate of genetic counseling and prenatal diagnosis in families with mtDNA disease (27). mtDNA is transmitted maternally, but the risk of transmitting mutated mtDNA through the germline is dependent on the type of mutation and possibly segregation of the mutation within the tissues of the mother. Currently, genetic and prognostic counselling is guided by the level of mtDNA heteroplasmy in the mother's tissues, including primary oocytes (28). Although oocyte sampling was not an option in this

family, the mother was prepared to undergo muscle biopsy and mutation screening of several other tissues. We were unable to detect any evidence of the MTNDl inversion or a biochemical abnormality in any of these tissues including muscle. Together, these data suggested that the inversion was behaving like a sporadic mtDNA mutation. Detailed studies of large cohorts of patients provide invaluable information on the risk of transmission. A recent analysis of 226 families in which the proband presented with a single, large-scale mtDNA deletion, the most prevalent group of sporadic, pathogenic mtDNA mutations, determined that the risk of recurrence in the offspring of an affected mother was $4.11 \%$ (29). Furthermore, if the mother was unaffected, the proband's siblings were similarly unaffected, suggesting a negligible recurrence risk. On this basis, the parents were counseled that it was extremely unlikely that they would have another affected child, and they now have a 9-mo-old daughter who is healthy with no signs of clinical symptoms.

In conclusion, this dramatic clinical presentation in association with an unusual mtDNA mutation highlights the everexpanding phenotypic spectrum of mitochondrial disease and strongly argues that we are not yet scraping the bottom of the barrel in terms of determining either genotype-phenotype correlations or the true impact of mtDNA mutations on human health (30).

\section{REFERENCES}

1. DiMauro S, Schon EA 2003 Mitochondrial respiratory-chain diseases. N Engl J Med 348:2656-2668

2. Taylor RW, Turnbull DM 2005 Mitochondrial DNA mutations in human disease. Nat Rev Genet 6:389-402

3. Kirby DM, Crawford M, Cleary MA, Dahl HH, Dennett X, Thorburn DR 1999 Respiratory chain complex I deficiency: an underdiagnosed energy generation disorder. Neurology 52:1255-1264

4. Shoubridge EA 2001 Nuclear genetic defects of oxidative phosphorylation. Hum Mol Genet 10:2277-2284

5. Loeffen JL, Smeitink JA, Trijbels JM, Janssen AJ, Triepels RH, Sengers RC, van den Heuvel LP 2000 Isolated complex I deficiency in children: clinical, biochemical and genetic aspects. Hum Mutat 15:123-134

6. Kirby DM, Salemi R, Sugiana C, Ohtake A, Parry L, Bell KM, Kirk EP, Boneh A Taylor RW, Dahl HH, Ryan MT, Thorburn DR 2004 NDUFS6 mutations are a novel cause of lethal neonatal mitochondrial complex I deficiency. J Clin Invest 114:837845

7. Kirby DM, Kahler SG, Freckmann ML, Reddihough D, Thorburn DR 2000 Leigh disease caused by the mitochondrial DNA G14459A mutation in unrelated families. Ann Neurol 48:102-104

8. Taylor RW, Morris AA, Hutchinson M, Turnbull DM 2002 Leigh disease associated with a novel mitochondrial DNA ND5 mutation. Eur J Hum Genet 10:141-144

9. Chol M, Lebon S, Benit P, Chretien D, de Lonlay P, Goldenberg A, Odent S, Hertz-Pannier L, Vincent-Delorme C, Cormier-Daire V, Rustin P, Rotig A, Munnich A 2003 The mitochondrial DNA G13513A MELAS mutation in the NADH dehydrogenase 5 gene is a frequent cause of Leigh-like syndrome with isolated complex I deficiency. J Med Genet 40:188-191

10. Lebon S, Chol M, Benit P, Mugnier C, Chretien D, Giurgea I, Kern I, Girardin E, Hertz-Pannier L, de Lonlay P, Rotig A, Rustin P, Munnich A 2003 Recurrent de novo mitochondrial DNA mutations in respiratory chain deficiency. J Med Genet 40:896-899

11. Kirby DM, Boneh A, Chow CW, Ohtake A, Ryan MT, Thyagarajan D, Thorburn DR 2003 Low mutant load of mitochondrial DNA G13513A mutation can cause Leigh's disease. Ann Neurol 54:473-478

12. Ugalde C, Triepels RH, Coenen MJ, van den Heuvel LP, Smeets R, Uusimaa J, Briones P, Campistol J, Majamaa K, Smeitink JA, Nijtmans LG 2003 Impaired complex I assembly in a Leigh syndrome patient with a novel missense mutation in the ND6 gene. Ann Neurol 54:665-669

13. McFarland R, Kirby DM, Fowler KJ, Ohtake A, Ryan MT, Amor DJ, Fletcher JM, Dixon JW, Collins FA, Turnbull DM, Taylor RW, Thorburn DR 2004 De novo mutations in the mitochondrial ND3 gene as a cause of infantile mitochondrial encephalopathy and complex I deficiency. Ann Neurol 55:58-64

14. Crimi M, Papadimitriou A, Galbiati S, Palamidou P, Fortunato F, Bordoni A, Papandreou U, Papadimitriou D, Hadjigeorgiou GM, Drogari E, Bresolin N, Comi GP 2004 A new mitochondrial DNA mutation in ND3 gene causing severe Leigh syndrome with early lethality. Pediatr Res 55:842-846 
15. Kirby DM, McFarland R, Ohtake A, Dunning C, Ryan MT, Wilson C, Ketteridge D, Turnbull DM, Thorburn DR, Taylor RW 2004 Mutations of the mitochondrial NDI gene as a cause of MELAS. J Med Genet 41:784-789

16. Thorburn DR, Sugiana C, Salemi R, Kirby DM, Worgan L, Ohtake A, Ryan MT 2004 Biochemical and molecular diagnosis of mitochondrial respiratory chain disorders. Biochim Biophys Acta 1659:121-128

17. Musumeci O, Andreu AL, Shanske S, Bresolin N, Comi GP, Rothstein R, Schon EA, DiMauro S 2000 Intragenic inversion of mtDNA: a new type of pathogenic mutation in a patient with mitochondrial myopathy. Am J Hum Genet 66:1900-1904

18. Taylor RW, Turnbull DM 1997 Laboratory diagnosis of mitochondrial disease. In: Applegarth DA, Dimmick J, Hall JG (eds) Organelle diseases. Chapman \& Hall, London, pp 341-350

19. Taylor RW, Taylor GA, Durham SE, Turnbull DM 2001 The determination of complete human mitochondrial DNA sequences in single cells: implications for the study of somatic mitochondrial DNA point mutations. Nucleic Acids Res 29:e74

20. King MP, Attardi G 1989 Human cells lacking mtDNA: repopulation with exogenous mitochondria by complementation. Science 246:500-503

21. Hofhaus G, Shakeley RM, Attardi G 1996 Use of polarography to detect respiratory defects in cell cultures. Methods Enzymol 264:476-483

22. Villani G, Attardi G 2001 In vivo measurements of respiration control by cytochrome c oxidase and in situ analysis of oxidative phosphorylation. Methods Cell Biol 65:119-131

23. Nijtmans LG, Henderson NS, Holt IJ 2002 Blue native electrophoresis to study mitochondrial and other protein complexes. Methods 26:327-334
24. Blakely EL, He L, Taylor RW, Chinnery PF, Lightowlers RN, Schaefer AM, Turnbull DM 2004 Mitochondrial DNA deletion in "identical" twin brothers. J Med Genet $41 ; \mathrm{e} 19$

25. Zickermann V, Barquera B, Wikström M, Finel M 1998 Analysis of the pathogenic human mitochondrial mutation ND1/3460, and mutations of strictly conserved residues in its vicinity, using the bacterium Paracoccus denitrificans. Biochemistry 37:11792-11796

26. Andreu AL, Hanna MG, Reichmann H, Bruno C, Penn AS, Tanji K, Pallotti F, Iwata S, Bonilla E, Lach B, Morgan-Hughes J, DiMauro S 1999 Exercise intolerance due to mutations in the cytochrome $b$ gene of mitochondrial DNA. N Engl J Med 341:1037-1044

27. Poulton J, Marchington DR 2000 Progress in genetic counselling and prenatal diagnosis of maternally inherited mtDNA diseases. Neuromuscul Disord 10:484 487

28. Poulton J, McShane A, Pike M, Seller A, Marchington DR, Kennedy S, Brown GK 2001 Advances in genetic management of patients with mitochondrial disease. J Neurol Sci 187:S435

29. Chinnery PF, DiMauro S, Shanske S, Schon EA, Zeviani M, Mariotti C, Carrara F, Lombes A, Laforet P, Ogier H, Jaksch M, Lochmuller H, Horvath $\mathrm{R}$, Deschauer M, Thorburn DR, Bindoff LA, Poulton J, Taylor RW, Matthews JN, Turnbull DM 2004 Risk of developing a mitochondrial DNA deletion disorder. Lancet 364:592-596

30. DiMauro S 2004 Mitochondrial medicine. Biochim Biophys Acta 1659:107-114 